\title{
Durable Solutions for IDPs in Afghanistan
}

A secondary data analysis 


\section{Durable Solutions - Some analysis}

- 2008 IDP Profiling (UNHCR/ MORR)

$\rightarrow \mathbf{9 7 \%}$ of surveyed Minarets IDPs (Herat) had no intention to return; IDPs in Maslakh expressed similar views

- 2011 Survey UNHCR World Bank

$\rightarrow$ More than $90 \%$ of IDPs reported plans to settle permanently in the city; irrespective of the conflict about $80 \%$ unwilling to return to their communities of origin due to lack of livelihood opportunities (unemployment, lack of land, food insecurity) 


\section{Durable Solutions - Some analysis}

- 2012 IDP Survey (NRC/ IDMC/ Samuel Hall)

$\rightarrow$ Survey sampling in Faryab,

Graph 23. What is your plan for the future?

Heart, Kabul, Kandahar,

Jalalabad

$\rightarrow 76.2 \%$ respondents prefer to settle permanently in their current location

$\rightarrow 23.3 \%$ willing to return

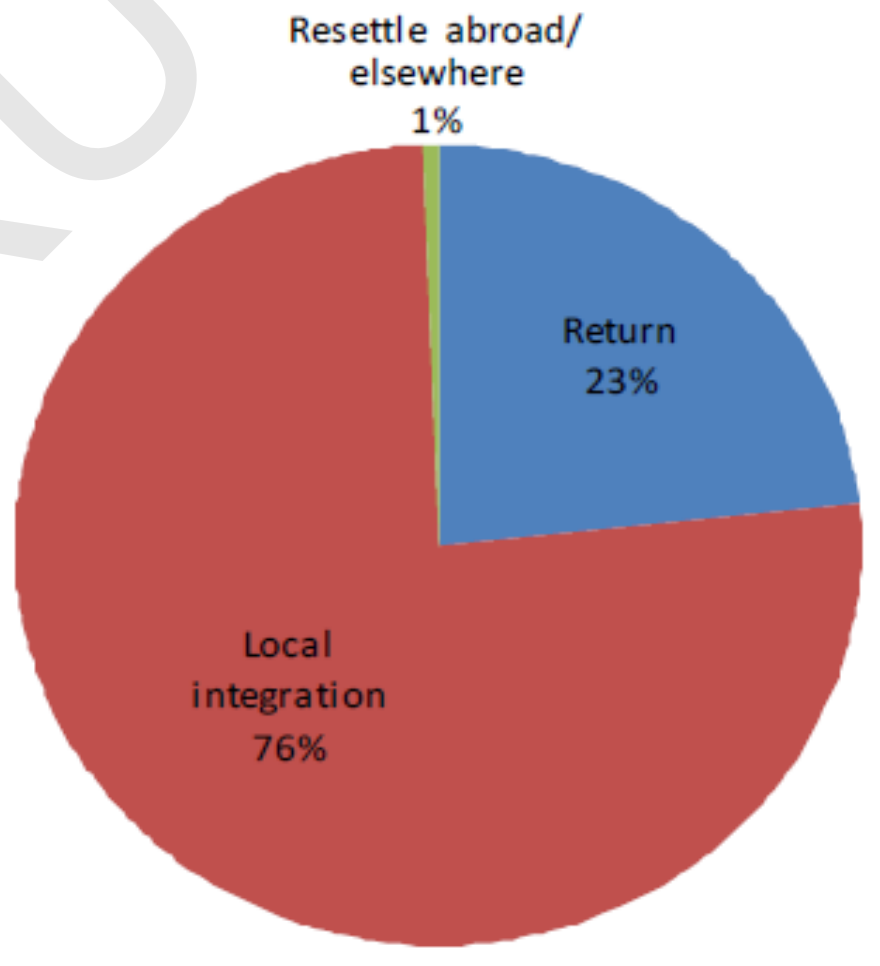




\section{Durable Solutions - Some analysis}

$\rightarrow$ Issues to facilitate a durable local integration:

employment, access to basic services, housing/shelter and land issues and access to sufficient food and clean water

Graph 22. Self-identified primary protection priorities of those hoplng to locally Integrate

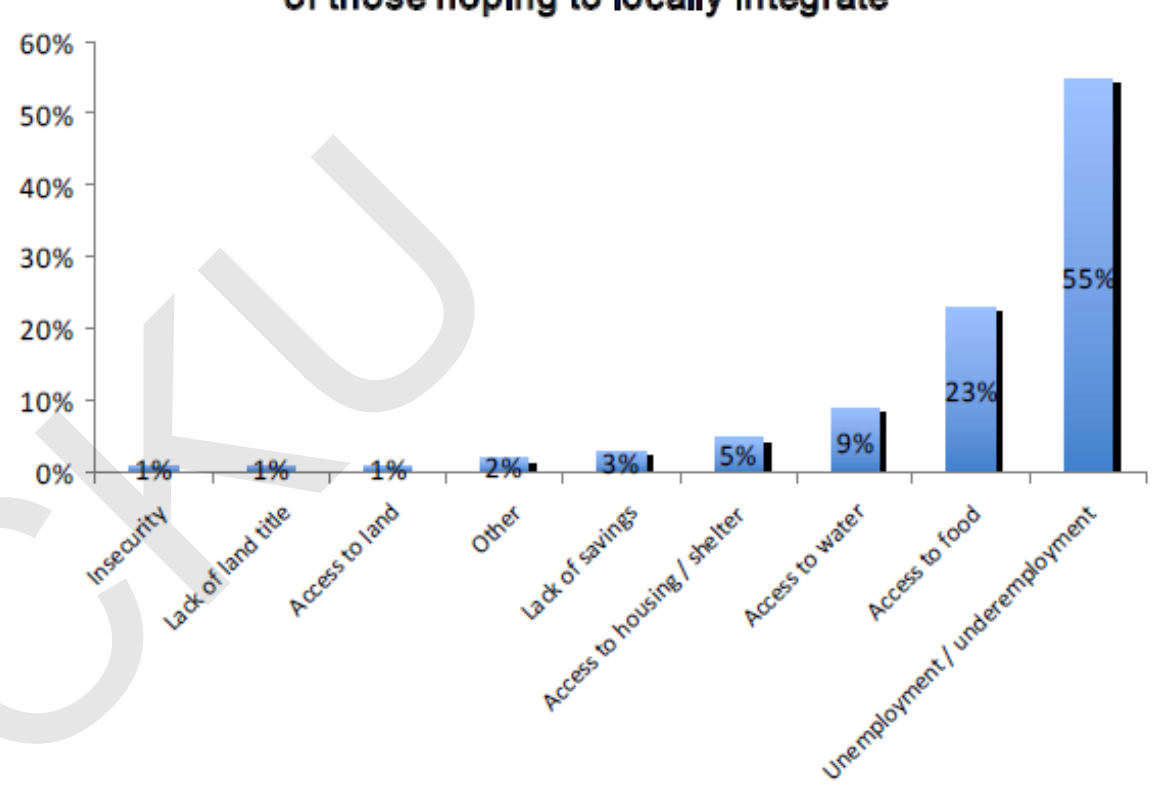

$\rightarrow$ Urban IDPs less interested in return as a solution: $40 \%$ cent willing to return located in urban areas VS some $60 \%$ were in rural $\rightarrow$ IDPs preferring local integration suffer less from un/ underemployment than others who pursue alternative solutions (55.1\% VS 76.3\%) 


\section{Durable Solutions - Some analysis}

$\rightarrow$ Desire to return reduces steadily over time: the longer families are displaced, the less interested they are in returning home

$\rightarrow 92 \%$ of surveyed IDPs wishing to return only when peaceful conditions prevail

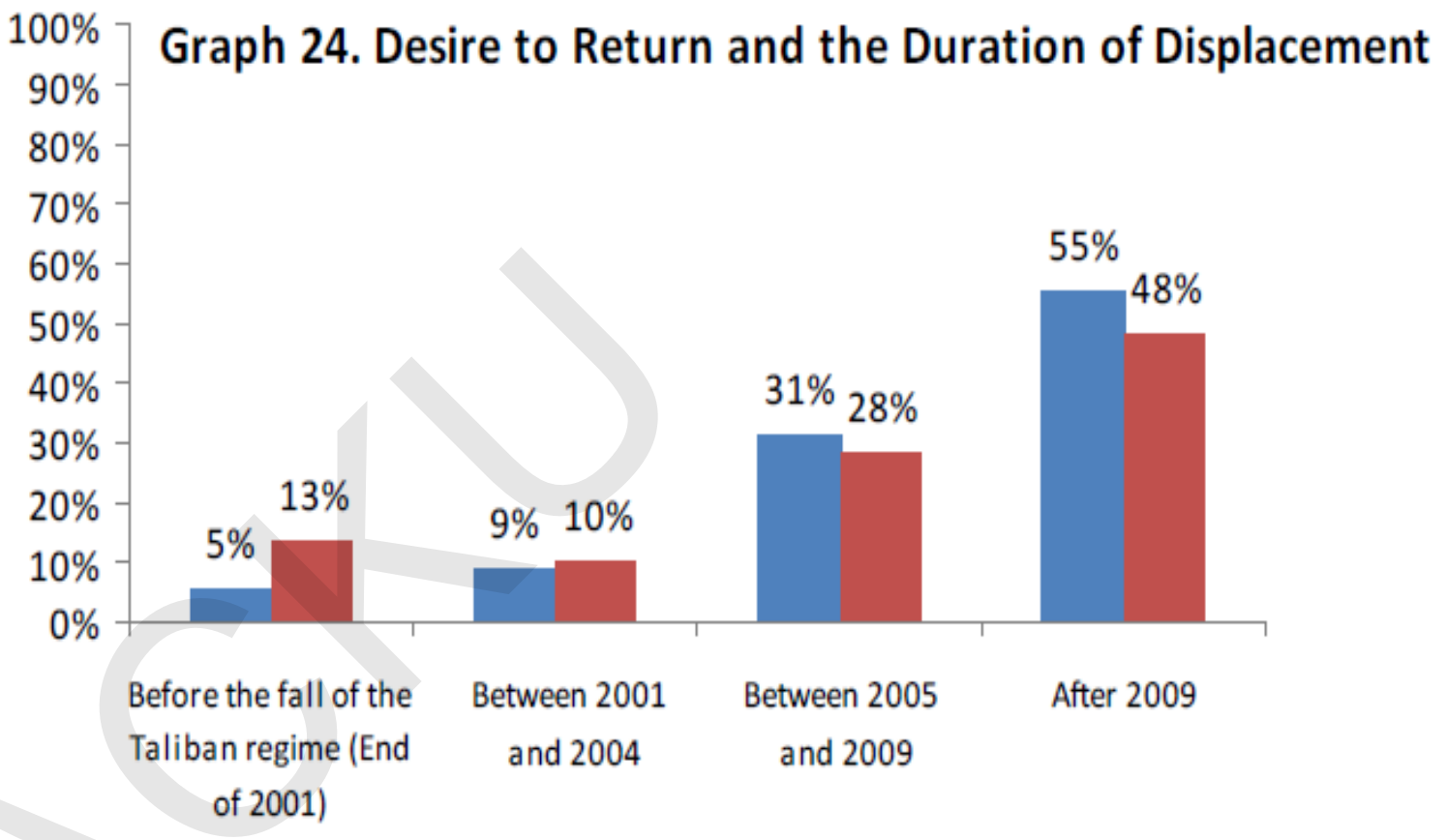

Table 5 On what conditions would you consider returning to your place of origin?

If it is secure

$22.9 \%$

If I find a job there $17.5 \%$

If I can get my land/house back

$11.8 \%$

Other

$2.3 \%$

Under no condition do I want to go back there

$74.7 \%$ 


\section{Durable Solutions - Some analysis}

$\rightarrow$ Shelter as a key problem for respondents choosing to return or settle: those who own single/shared residences prefer to settle locally, while those renting are interested in return

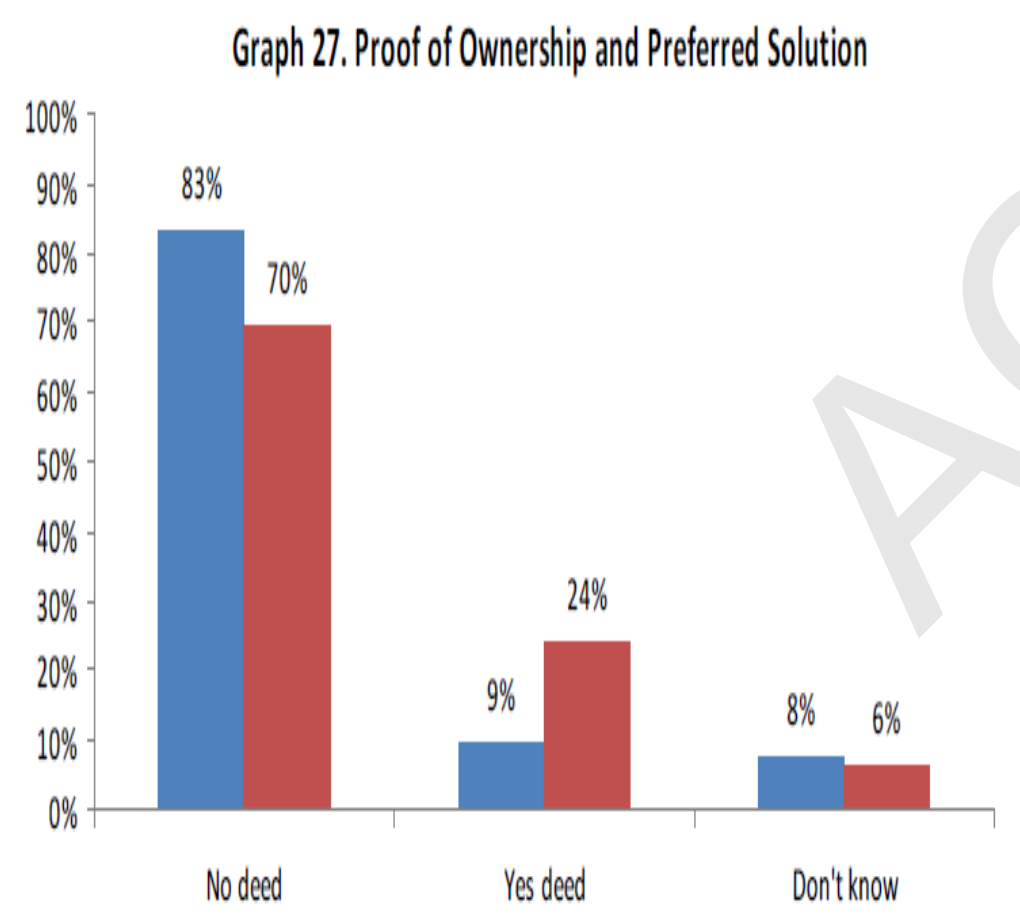

-Return\% LocallySettle\%
Graph 28. Type of Dwelling and Preferred Solution

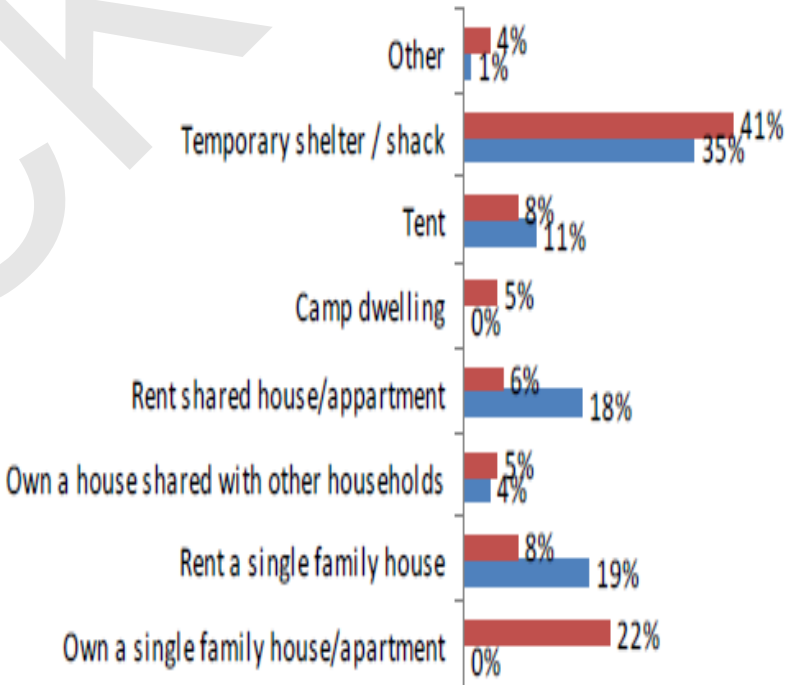

$0 \% \quad 10 \% \quad 20 \% \quad 30 \% \quad 40 \% \quad 50 \% \quad 60 \% \quad 70 \% \quad 80 \% \quad 90 \% \quad 100 \%$ 


\section{Durable Solutions - Some analysis}

- UNHCR IDP Survey 2012

$\rightarrow$ de facto local integration pursued by several IDP groups but lacking formal facilitation and recognition by the State. This results in continued protection risks (eviction, lack of legal identification documents, and limited access to services etc. )

- UNHCR IDPs Survey Kabul 2014

$\rightarrow$ Majority of IDPs do not intend to return to their places or origin Only $\mathbf{2 7 \%}$ willing to return when the situation permits (security, social services)

$\rightarrow$ More men than women expressed intentions to return

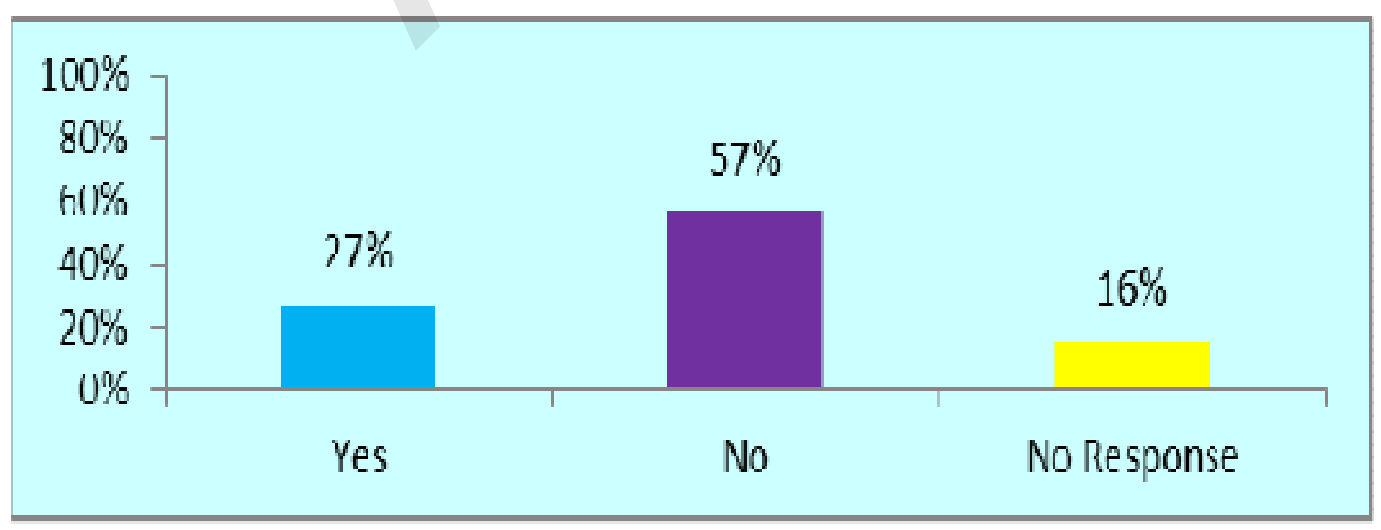




\section{Durable Solutions - Some analysis}

- DACAAR / Samuel Hall study 2015

$\rightarrow$ IDPs are not only driven by different push factors, they are also looking for emotional, physical and material gains in their migration and choice of a destination.

$\rightarrow$ IDPs motivated by security concerns regardless of where they go. For $90 \%$ of IDPs improved security situation as one of the main factor in choice of destination

$\rightarrow$ In almost $50 \%$ of cases, decision to move taken by the head of household alone. In almost 2/3 of the cases, women entirely excluded form decision making.

$\rightarrow$ IDPs motivated by security concerns regardless of where they go. For $90 \%$ of IDPs improved security situation as one of the main factor in choice of destination

$\rightarrow 92 \%$ of respondents (MIXED) consider local integration as the preferred durable solution. 


\section{Durable Solutions - Some analysis}

- DRC PIN Urban Poverty Report 2015

$\rightarrow 93 \%$ of urban households report having no intention to move again. Only $10 \%$ of IDP households would like to go back to their place of origin

\section{INTENTION TO MONE}

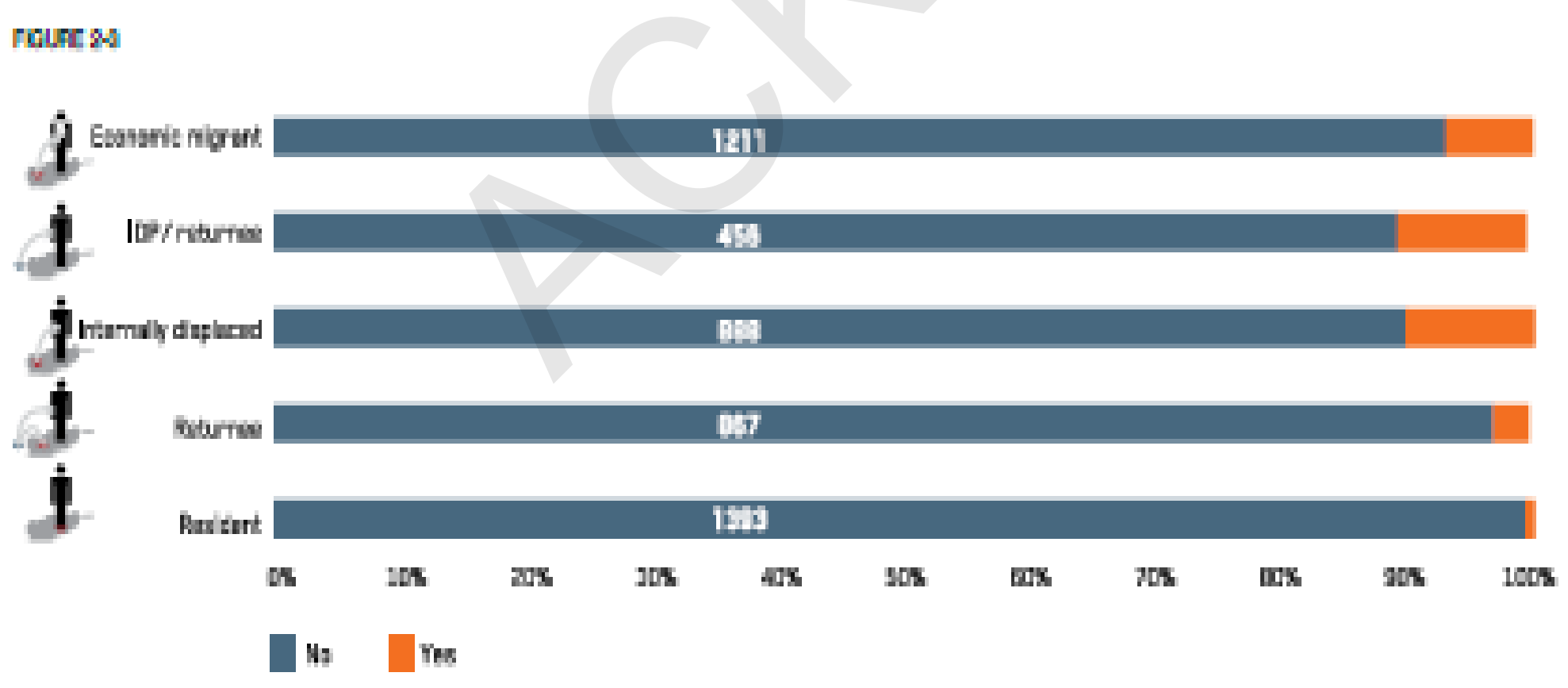




\section{Durable Solutions - Some analysis}

- PIN Baseline Study - Herat 2015

$\rightarrow$ Absolute majority of people intends to stay in Herat

$\rightarrow$ Security and services as key element for the few opting for return
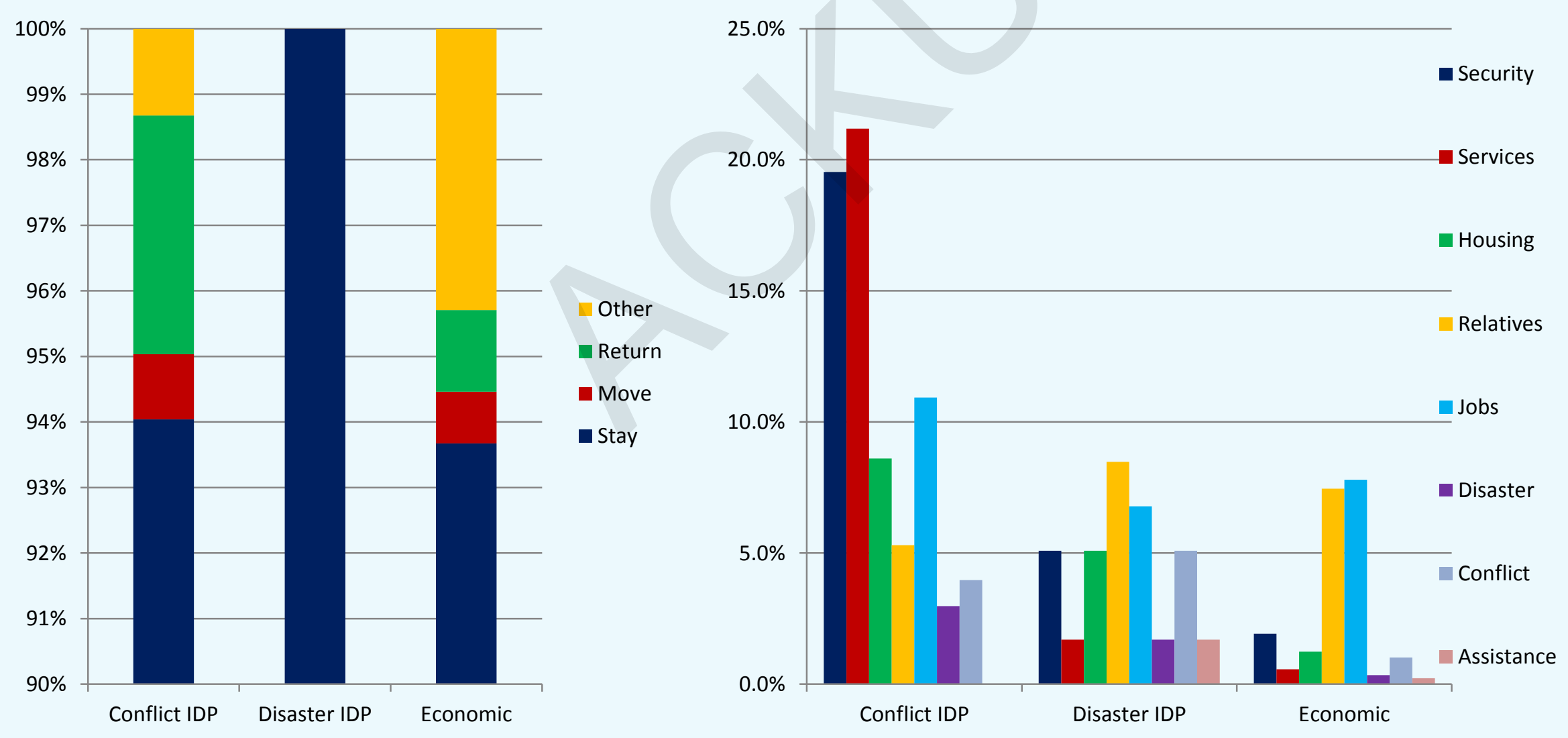


\section{Durable Solutions - Some analysis}

- $\quad$ PIN Baseline Study - Jalalabad 2015

$\rightarrow$ Absolute majority of people intends to stay in Jalalabad

$\rightarrow$ Variety of needs determine option for return
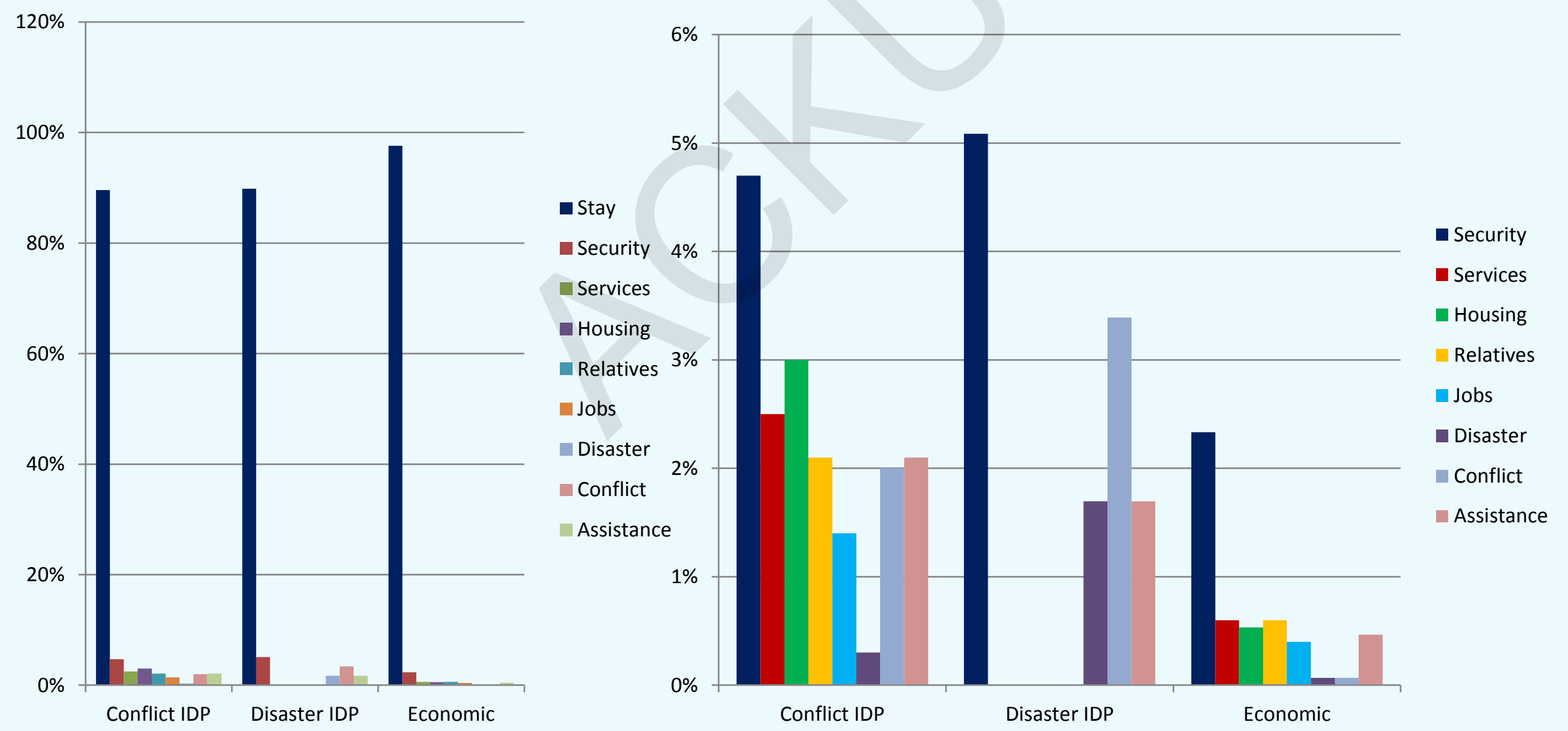